\title{
SUFFICIENT CONDITIONS FOR STARLIKENESS
}

\author{
Mamoru NunOKAWA, S.P. GOYAL AND RAKESH KumAR
}

\begin{abstract}
The purpose of the present paper is to consider some sufficient conditions for analytic functions in the open unit disk to be starlike. Here we establish three theorems by using Jack's lemma and a simple result contained in Lemma 2.2. Our theorems provide improvements of the results about sufficient conditions for starlike functions given earlier by Lewandowski et al. [2], Li and Owa [3], Nunokawa et al. [5] and Ramesha et al. [6].
\end{abstract}

Mathematics subject classification (2010): 30C55.

Keywords and phrases: Analytic functions, starlike functions.

\section{REFERENCES}

[1] I.S. JACK, Functions starlike and convex of order $\alpha$, J. London. Math. Soc. 2, 3 (1971), 469-474.

[2] Z. Lewandowski, S.S. Miller And E. ZlotkiewicZ, Generating functions for some classes of univalent functions, Proc. Amer. Math. Soc. 56 (1976), 111-117.

[3] Jian-Lin Li And S. Owa, Sufficient conditions for starlikeness, Indian J. Pure Appl. Math. 33, 9 (2002), 1385-1390.

[4] M. Nunokawa, On properties of Non-Carathéodory functions, Proc. Japan Acad. 68, 6 (1992), 152 153.

[5] M. Nunokawa, S.Owa, S.K. Lee, M. Obradovic, M.K. Aouf, H. Saitoh, H. IKada and N. KoIKA, Sufficient conditions for starlikeness, Chinese Journal of Mathematics 24 (1996), 265-270.

[6] C. Ramesha, S. Kumar And K.S. Padmanbham, A sufficient condition for starlikeness, Chinese J. Math. 23 (1995), 167-171. 